
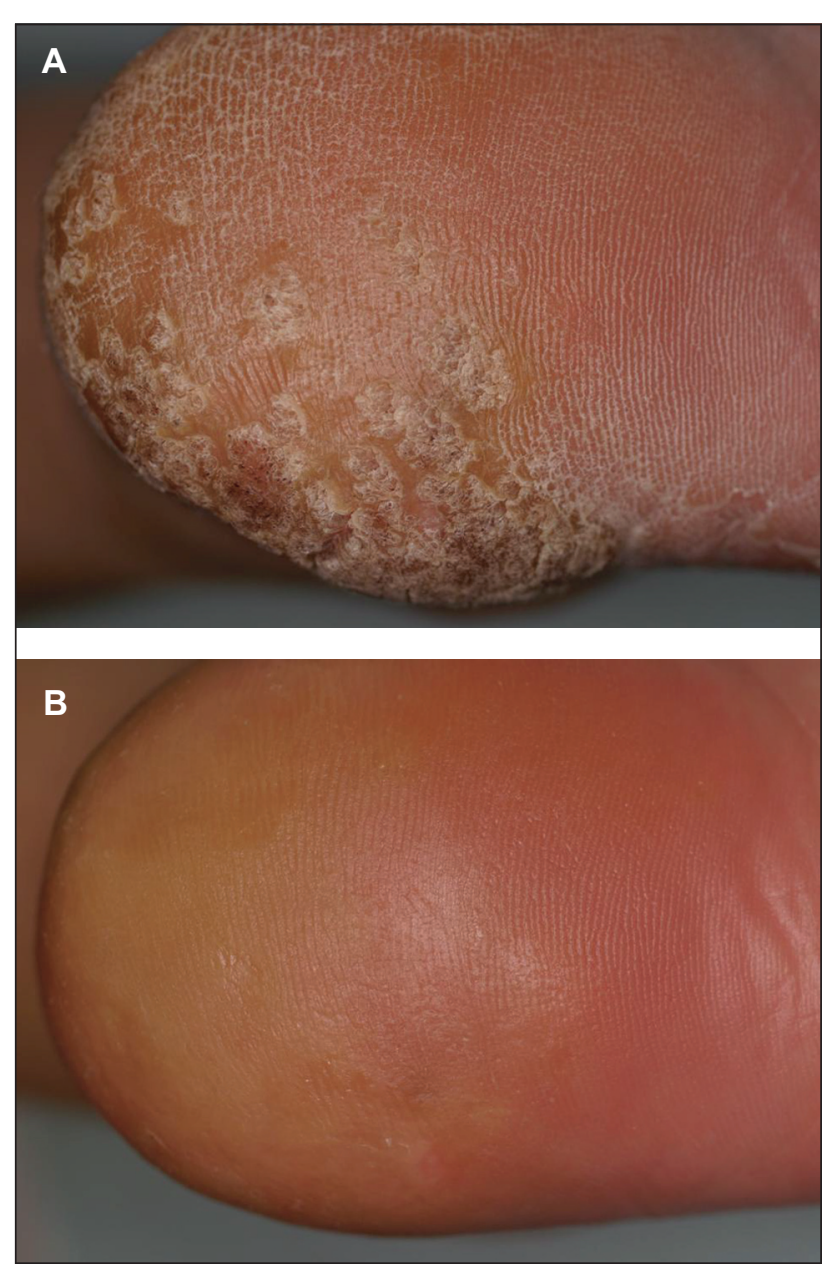

Figure 1. Clinical pictures of the recalcitrant mosaic plantar wart before (A) and after (B) treatment with topical 5\% imiquimod cream. Recalcitrant mosaic warts were predominantly seen on the left heel of the foot.

ment was continued for 16 weeks after the lesions had resolved (figure $1 B$ ).

Patient 2, a 30-year-old female, came to our hospital in February 2008. Previous treatment with liquid nitrogen cryosurgery was not effective for the lesional skin. Similarly, imiquimod was applied as a $5 \%$ cream three times per week and before the applications, lesions with a thick stratum corneum were removed by disposable razors. The lesional skin also showed clearance after 14 weeks of treatment with $5 \%$ imiquimod cream. Results of follow up examinations 3 months later showed no evidence of recurrence in either case.

The efficacy of topical 5\% imiquimod cream to treat cutaneous warts has been previously investigated in various studies $[5,6]$. However, to our knowledge, the efficacy of topical imquimod cream to treat mosaic plantar warts has not often been reported [3,4]. According to several reports with large scale studies, the average clearance rates ranged from $27 \%$ to $30 \%$ in immunocompetent patients with cutaneous warts, including mosaic plantar warts $[5,6]$. Imiquimod works by agonistic actions on toll-like receptor-7 in monocytes and $\alpha$-dendritic cells of the epidermis. Therefore this cream is not effective to treat lesional skin with a thick stratum corneum. We removed the thick stratum corneum by using disposal razors before applying 5\% imiquimod cream, which resulted in better penetration of the cream into the epidermis to bind to toll-like receptor-7 in monocytes and $\alpha$-dendritic cells. Local skin reactions are well known, and local pruritus, especially, is very common, irrespective of indications. Other skin reactions, e.g., burning, irritation, erythema, erosion, ulcer, pain, bleeding, and paraesthesia are also known [1]. However, those reactions depend on the anatomical sites. There were no severe skin reactions except for pruritus and slight pain in our cases. In our experience, topical imiquimod cream and disposable razors to remove the thick stratum corneum are an effective option for treatment of recalcitrant mosaic plantar warts in adults.

Acknowledgements. Conflict of interest: none. Financial support: none.
Department of Dermatology, Nippon

Medical School, 1-1-5 Sendagi,

Bunkyou-ku Tokyo, 113-8603,

Japan

<tmitsu@nms.ac.jp >
Tsuyoshi MITSUISHI

Toshiteru

WAKABAYASHI

Seiji KAWANA
1. Wagstaff AJ, Perry CM. Topical imiquimod: a review of its use in the management of anogenital warts, actinic keratoses, basal cell carcinoma and other skin lesions. Drugs 2007; 67: 2187-210.

2. Gross G, Majewski S. Skin diseases with high public health impact. Warts. Eur J Dermatol 2008; 18: 111-2.

3. Zamiri M, Gupta G. Plantar warts treated with an immune response modifier: a report of two cases. Clin Exp Dermatol 2003; 28: 45-7.

4. Yesudian PD, Parslew RA. Treatment of recalcitrant plantar warts with imiquimod. J Dermatolog Treat 2002; 13: 31-3.

5. Grussendorf-Conen El, Jacobs S, Rübben A, Dethlefsen U. Topical $5 \%$ imiquimod long-term treatment of cutaneous warts resistant to standard therapy modalities. Dermatology 2002; 205: 139-45.

6. Hengge UR, Esser S, Schultewolter T, Behrendt C, Meyer T, Stockfleth $E$, Goos $M$. Self-administered topical $5 \%$ imiquimod for the treatment of common warts and molluscum contagiosum. Br J Dermatol 2000; 143: 1026-31.

doi:10.1684/ejd.2009.0637

\section{Severe proctitis due \\ to lymphogranuloma venereum (Chlamydia trachomatis)}

In June 2007, a 54-year-old HIV1 positive man from Lisbon presented with a 3-month history of rectal pain, mucopurulent rectal discharge, rectal bleeding, tenesmus, weight loss $(8 \mathrm{~kg})$ and generalized weakness. He was on antiretroviral therapy $\left(\right.$ Combivir $^{\circledR}+$ Telzir $^{\circledR}+$ Norvir $\left.^{\circledR}\right)$ with a CD4 count of $1158 \mathrm{cell} / \mathrm{mm}^{3}$ and a viral load of $<50$ copies $/ \mathrm{mL}$. He had several stool cultures that showed no enteric pathogens. A sigmoidoscopy and later, a colonoscopy (figure 1), showed multiple rectal ulcers; histological examination revealed ulceration with mixed acute and chronic inflammatory cells and a lymphoid infiltrate. He was treated with metronidazol (several courses) but his symptoms failed to resolve. He was then referred to our dermatovenereology department for screening of enteric sexually transmitted diseases.

The patient had had at least 4 anonymous sex partners in the previous 6 months and regular anal-receptive intercourse without condoms. VDRL, TPHA, VHB and VHC 


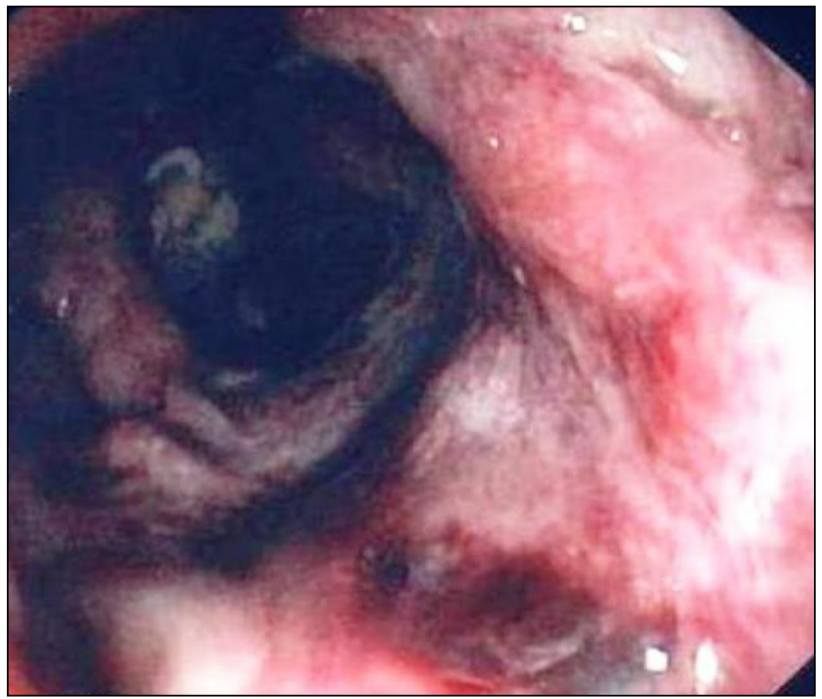

Figure 1. Colonoscopy showing multiple ulcerative lesions in the anorectal area.

serology were performed. Serology for Chlamydia trachomatis showed a titer of 1:1024 (IgG), $\operatorname{IgM}<16$ and $\operatorname{IgA}$ 1:32. VDRL was reactive $(1 / 32)$ and TPHA was positive. We performed a rectal swab that was tested for Neisseria gonorrhoeae, Chlamydia trachomatis, herpes simplex virus 1 and 2 and Treponema pallidum, through commercial nucleic acid amplification tests (Cobas-Amplicor and Sacace), performed according to manufacturers' instructions. Chlamydia trachomatis and Treponema pallidum were both detected and further molecular biological studies of the Chlamydia trachomatis isolate (ompA genotyping) confirmed the infection with a new lymphogranuloma venereum (LGV) variant (different from all the described to date) associated with recent syphilis. In the C. trachomatis ompA gene, our strain presents 3 nucleotide changes to $\mathrm{L}_{2}-434$ (which is the $\mathrm{L}_{2}$ prototype strain), 1 nucleotide change to $\mathrm{L}_{2 \mathrm{~b}}-144276$ and 2 nucleotide changes to the recently described $\mathrm{L}_{2 \mathrm{c}}$. Treatment with $100 \mathrm{mg}$ oral doxycycline twice daily for 3 weeks and a single dose of benzatinic penicillin $(2.400 .000 \mathrm{U})$ was effective. Test of cure was performed 5 weeks after treatment and was negative. LGV is caused by the L1, L2 and L3 serovars of Chlamydia trachomatis and was previously confined to endemic areas in tropical regions. However, since 2003, a cluster of LGV cases presenting with anorectal symptoms in MSM has been reported in Rotterdam. This was followed by a series of case reports in various cities in Western Europe and the United States. Most of these patients presented with rectal symptoms and only a few with inguinal lesions. The majority of patients were co-infected with HIV, and high levels of co-infection with sexually transmitted bacterial infections and hepatitis $\mathrm{C}$ were also reported [1-3]. The majority reported large numbers of sexual partners and unprotected anal intercourse. Therefore, as in our patient, contact tracing has been of limited use so far. This is the first rectal LGV case reported in Portugal; Chlamydia trachomatis (L2 serovar) has previously been isolated from urogenital samples in another 5 patients.

As in the case of our patient, a diagnostic delay has been common as many doctors are unfamiliar with this condi- tion. Endoscopic features are non-specific, with a wide range of differential diagnoses including Crohn's disease, anorectal carcinoma and other non-sexually and sexually transmitted infections. Most guidelines $[4,5]$ have suggested that first-line treatment is doxycycline $100 \mathrm{mg}$ twice daily for 21 days (erythromycin $500 \mathrm{mg}, 4$ times daily, 21 days is an alternative). We treated our patient first with penicillin and introduced doxycycline when we received nucleic acid amplification tests.

A diagnostic delay is common in this condition and LGV cases may easily be missed if LGV is not considered during diagnosis or if appropriate diagnostic tools are not available. This condition is an important sentinel event with serious implications for the patient and for public health. For these reasons, it is important to consider this diagnosis when seeing MSM with bowel symptoms.

Acknowledgements. We thank the Chlamydia-Neisseria unit of the National Institute of Health, Lisbon, Portugal for the molecular diagnosis support and molecular characterization strains. Financial support: none. Conflict of interest: none.
${ }^{1}$ Faro Hospital Dermatology

Department, Hospital Central de

Faro, Rua Leão, Penedo 8000 Faro,

Portugal

${ }^{2}$ Dermatovenereology Department,

Lisbon, Portugal

${ }^{3}$ Infectious Disease Department,

Lisbon, Portugal

<ricardolaocoelho@yahoo.com>
Ricardo COELHO Candida FERNANDES ${ }^{2}$ Joao MACHADO ${ }^{3}$ Fernanda CORREIA ${ }^{3}$ Teresa MARTINS ${ }^{3}$ Jorge CARDOSO ${ }^{2}$
Fernando MALTEZ ${ }^{3}$

1. Nieuwenhuis RF, Ossewaarde JM, Gotz HM, et al. Resurgence of lymphogranuloma venereum in Western Europe: an outbreak of Chlamydia trachomatis serovar L2 proctitis in The Netherlands among men who have sex with men. Clin Infect Dis 2004; 39: 996-1003.

2. Van der Bii AK, Spaargaren J, Morre SA, et al. Diagnostic and clinical implications of anorectal lymphogranuloma venereum in men who have sex with men: a retrospective case-control study. Clin Infect Dis 2006; 42: 186-94.

3. Ranki A. HIV infection. Eur J Dermatol 2008; 18: $217-9$

4. CDC guidelines for LGV (www.cdc.gov/STD/treatment/).

5. McMillan A, van Voorst Vader PC, de Vries HJ. The 2007 European guideline (IUSTI/WHO) on the management of proctitis, proctocolitis and enteritis caused by sexually transmissible pathogens. Int J STD AIDS 2007; 18: 514-20.

doi: $10.1684 /$ ejd.2009.0638

\section{A novel missense mutation of the DSRAD gene in a Chinese family with dyschromatosis symmetrica hereditaria}

Dyschromatosis symmetrica hereditaria (DSH; MIM127400) is an autosomal dominant skin disorder characterized by a mixture of hyperpigmented and hypopigmented macules of various sizes on the back of the hands and feet. Many patients with DSH also have small freckle-like pigmented macules on their faces. These clinical features usually appear in infancy or early childhood, commonly stop spreading before adolescence, and last for life. The DSH locus has been mapped to chromosome 1q21 and then, in 2003, pathogenic mutations were identified in the double-stranded RNA-specific adenosine 